\title{
New Materials, Processes and design Methods for the Chip Mounting of High-Temperature Sensors
}

\author{
N.Subbiah ${ }^{1}$, M.Feißt $^{2}$, R.Zeiser ${ }^{2}$ E.Möller ${ }^{2}$, J.Wilde \\ Laboratory for Assembly and Packaging Technology, Department of Microsystems Engineering,, \\ University of Freiburg, Georges-Koehler-Allee 103, Germany \\ subbiah@imtek.de
}

\begin{abstract}
In this research work, a comparison of different die attachment approaches is established. The approaches involve electrically conductive adhesive, transient liquid phase bonding, silver sintering and glass bonding. The main target is to minimize mechanical stresses due to die attachment process temperatures and differences in the coefficients of thermal expansion (CTE). Therefore test chips and sensors are mounted onto various ceramic substrates as AIN, Alumina, AIN DCB using area contact geometries for die attachment.

In our work, different sensors and power devices especially designed for working up to $500^{\circ} \mathrm{C}$ are used as the die element. A comparative study is performed with variations of materials, assembly and die attachment techniques. Experimental results and process parameters are presented for individual approaches. Also a method to stress modeling of the assembly using optical digital image correlation is given.
\end{abstract}

Key words: Ceramics,High temperature,Die attachment,Adhesives,TLP,Sintering.

\section{Introduction}

In industry there is an increasing demand for reliable pressure sensors for applications in harsh environment up to $500{ }^{\circ} \mathrm{C}$. Pressure sensors for such high temperatures impose new challenges in packaging. One of the primary reasons is the existence of temperature induced stresses in the package which affect reliability and thermal cross sensitivity. Major issues of the packaging work are to identify stable materials at high temperature and lowstress sensor mounting techniques. Several new materials for high temperature packaging must be suitably chosen to solve the performance and reliability problems. The thermomechanical stresses normally arises from the CTE mismatch of the material choices and [1] and also due to the process temperatures. The properties of different die attachment techniques are investigated as part of this work for specific applications. The results are compared to give overall picture about high temperature packaging.

\section{Die attachment Materials}

Die attachment in assembly of electronic and MEMS devices acts as a mechanical support between the substrate and the die,[2] it also enable to have electrical connecting to the active chip element. Die attachment materials and mounting techniques are selected according the application requirements. Different die attachments techniques and its relevant material choices and properties are discussed below. In this work, GaN, SiC is predominantly used as the high temperature substrate material. Alumina, AIN DCB are used as the substrate material. The properties of these materials are given in the Table 1.

Tab. 1: Properties of the material choices[2][6]

\begin{tabular}{|c|c|c|c|c|}
\hline & $\mathrm{Si}$ & $\mathrm{Al}_{2} \mathrm{O}_{3}$ & $\mathrm{AlN}$ & $\mathrm{GaN}$ \\
\hline$\alpha[\mathrm{ppm} / \mathrm{K}]$ & 2.6 & 7.3 & 5.2 & $3: 17$ \\
\hline$\lambda[\mathrm{W} / \mathrm{mK}]$ & 150 & 24 & 170 & 130 \\
\hline
\end{tabular}




\section{Die attach processes}

In this section, different die attachment methods are discussed with an example of real world applications. The processes, material choices and its advantages are given.

\section{Electrical conductive adhesive}

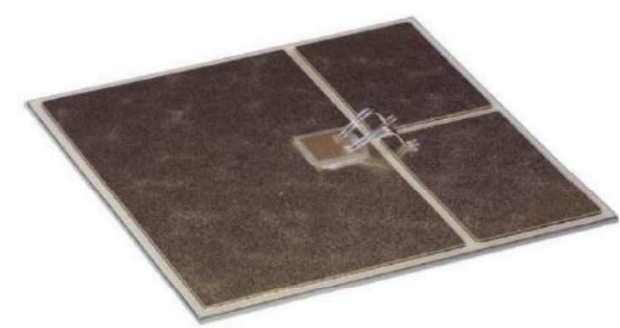

Fig. 1. DCB substrate with an assembled diode using electrical conductive adhesive. [1]

Figure 1 shows a SiC based schottky diodes are die attached to the AIN DCB substrate with electrical conductive adhesives (Heraus) The adhesive is a mix of epoxy and silver flakes with a mass contents of approximately $80 \%$. This method has low process induced stresses in the assembly due to low curing temperature $120^{\circ} \mathrm{C}-180^{\circ} \mathrm{C} .[1][2]$ The adhesive is typically pressure dispensed to the substrate and a pick and place machine is used to place the die and apply necessary pressure to establish the mechanical contact. A $300 \mu \mathrm{m}$ Al wire ( Heraus AIX) bonded for electrical interconnection.[1][2][5]

\section{Transient Liquid Phase Bonding}

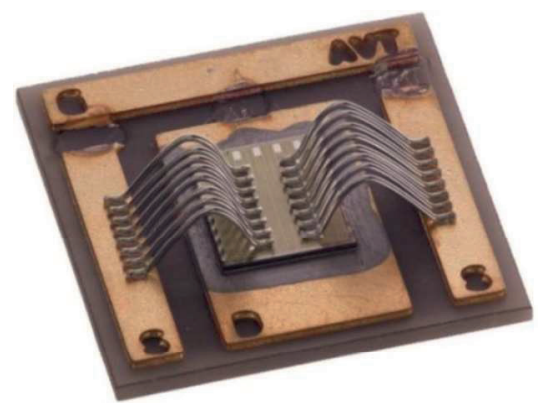

Fig. 2. GaN based RF transistor TLP bonded on Ain $D B C$ [1]

Transient Liquid Phase (TLP) is commonly known as Solid Liquid Inter-Diffusion (SLID) process. Advantages of this technique are formation of high-melting binary phase alloys, void-free interfaces, and flux-less joining [1, 5, 7]. Figure 2 shows the GaN based RF transistor TLP bonded to AIN DCB.

$\mathrm{Ag}-\mathrm{Sn}$ multilayer foil was used as the inter layer material, which is sandwiched between the chip and substrate. In the substrate bonder, A pressure of $5 \mathrm{MPa}$ is applied in combination with temperature $\left(240{ }^{\circ} \mathrm{C}\right)$ using the top and the bottom heating plates. Tin melts and diffuses into the silver to form high-temperature stable binary alloys. The assembly is kept at the bonding temperature and pressure until isothermal solidification of Sn-Ag binary alloy takes place. An optional annealing step is often deployed for bond homogenization. TLP bonded dies are stable to operate up to $500{ }^{\circ} \mathrm{C}$. [1][2][5]

\section{Silver Sintering}

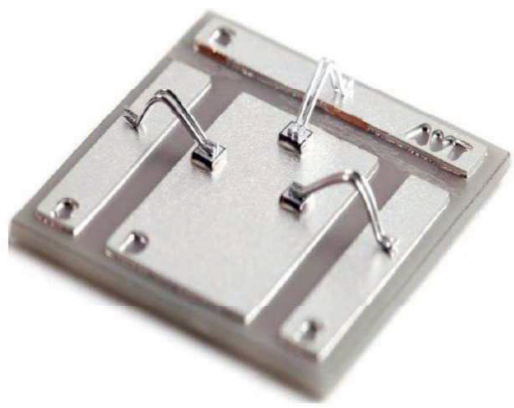

Fig. 3. SiC Schottky diodes attached onto an AINDCB using silver sintering.[2]

Figure 3 shows the SiC based Schottky diode silver sintered to AIN DCB, silver sintering has been established as one of the most promising die-attach technology for power devices, Silver sintering process requires low bonding temperature $\left(220^{\circ} \mathrm{C}\right)$ and this helps to minimize the process induced stresses. A micro-scaled silver paste LTS 275-3P2 from Heraeus $\mathrm{GmbH}$ was used as sintering material. The sintering paste is dispensed on to the substrate. Both the substrate and the backside of the die is deposited with noble metals. A hot press machine is used to sinter the die and substrate together. Resulting assembly can withstand temperatures upto $500^{\circ} \mathrm{C}$. [1][2][5]

\section{Glass soldering}

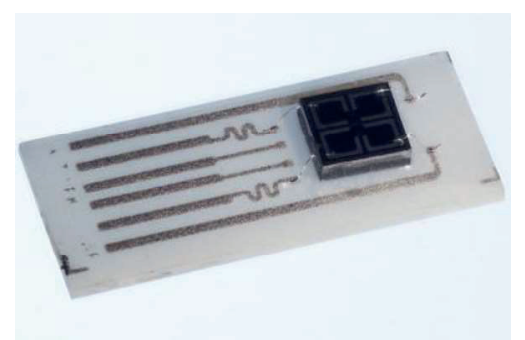

Fig. 4. SiC bases pressure sensor glass soldered to the Alumina ceramic.[4] 
Figure 4 shows the wire $\mathrm{SiC}$ pressure sensor die attached to the alumina substrate with Borosilicate based glass solder. The glass solder is cured at $700^{\circ} \mathrm{C}$. Glass solders are available with different CTE values [3][4]. Suitable glass solder must be carefully chosen matching the CTE of the substrate and die. This can help to reduce the stress development in the assembly due to high process temperatures. The operation temperature of a glass solder assembly is upto $650^{\circ} \mathrm{C}$. [3][4]

\section{Selecting suitable die attachment}

Comparison between the different die attachments techniques are discussed in this section, this work enables us to choose mounting techniques based on applications. The deciding parameters are process temperatures, Material choices, maximum operation temperatures and requirement of a substrate metallization. The stress modelling of the assembly and thermal management largely depends on these choices. Table 3 shows the different properties of die attachment techniques.

Machine requirement can also a factor in choosing the suitable die attachment technique. Electrical conductive adhesive and glass solder attachment can be used where substrate metallization is not possible. Experiments conducted on these different approaches and results are tabulated in Table 2.

In designing a high temperature assembly for power electronic devices, Thermal management is essential due to its active power heating. In this case a high thermal conductivity and low thermal resistance design is suitable. TLP and sintering based die attachment can be the appropriate choice in this case. In case of high temperature environment sensors, like SiC pressure sensor a glass solder based die attachment is suitable. It has high process temperatures and proven to be reliable for long time exposure in harsh environment.

\section{Design method - stress}

Due to the differences in the CTE of the substrate, chip and mounting material, the stresses developed in the assembly leads to deformation of the package The theoretical formula to calculate stress is given in Equation $1[6]$.

Equation 1: Thermal stress inside a Chip, induced by the packaging process, with geometric factor $\mathrm{C}[6]$
Tab. 2: Experiemental results of die attach methods[1][2]

\begin{tabular}{|l|c|c|c|}
\hline & $\begin{array}{l}\text { Bonding } \\
\text { strength } \\
\mathrm{MPa}\end{array}$ & $\begin{array}{c}\text { Thermal } \\
\text { conductivity } \\
\text { (W/mK) }\end{array}$ & $\begin{array}{c}\text { Thermal } \\
\text { resistance } \\
\text { K/W }\end{array}$ \\
\hline ECA & 38 & $15.61^{*}$ & 0.631 \\
\hline TLP & 36 & $51.38^{*}$ & 0.495 \\
\hline Sinter & 43 & $100^{*}$ & 0.498 \\
\hline $\begin{array}{l}\text { Glass } \\
\text { solder }\end{array}$ & 32 & $0.7^{*}-1.65^{*}$ & - \\
\hline
\end{tabular}

$\sigma=C \cdot\left(\alpha_{\text {Sub }}-\alpha_{\text {Chip }}\right) \cdot\left(T_{P R O}-T_{R}\right) \cdot\left[\frac{E_{\text {Sub }} \cdot E_{M} \cdot L_{\text {Chip }}}{d_{M}}\right]^{1 / 2}$

(1)

The key parameters for the stress inside a chip, induced by the package are: The difference between the process temperature $T_{P R O}$ and the regarded temperature $T_{R}$, in this case the roomtemperature, the CTE of the substrate $\alpha$ sub and chip achip, the Young's-Modulus of the substrate Esub and the mounting material $\mathrm{E}_{\mathrm{M}}$, the thickness of the die-attach layer $d_{M}$ and the length of the chips edge $L_{\text {Chip. }}$ [6]

The bending stress can be calculated by measuring the warpage of the mounted chip. [6].

$$
\sigma=\frac{E_{\text {Chip }} \cdot t}{2 R}
$$

Equation 2: Estimation of the bending stress in a chip dependent on the chips bending radius $R$, its thickness $t$ and its Young's-Modulus Echip [7]

Digital Image correlation technique can be used to measure the warpage of the packaged assembly. Figure 5 shows the DIC correlation images for the $z$ coordinate contours. The maximum out of plane warpage measured in this case is $4.8 \mu \mathrm{m}$ at the room temperature. The DIC optical measurement requires a speckle pattern coated on the samples to create the spatial resolution on the sample surface. Non destruction warpage measurements can also be performed using white light interferometer.[6] 

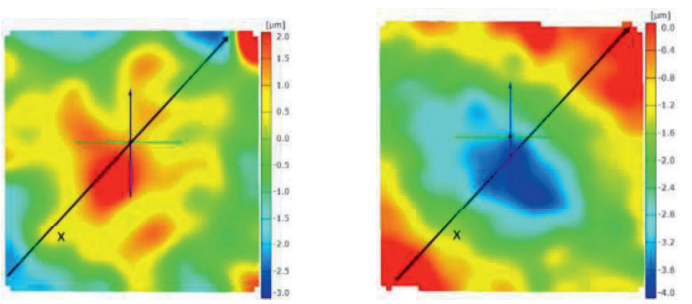

Fig. 5. DIC measurements- SiC sensor on AIN: Z coordinate contours at $25{ }^{\circ} \mathrm{C}$ (left), Contours of $\Delta z$ from $25-500{ }^{\circ} \mathrm{C}$ of sensor (right). [3]

\section{Conclusion}

In this work, different die attachment techniques for high temperature application are discussed and its processes and material choices are established. Each die attachment technique is discussed with an example in different application areas. Which gives insight into the scope of its application in high temperature packaging regime. The values listed in the table make the comparison between different approaches. An example of stress modelling for the assembly is shown. Electrical conductive adhesive, transient liquid phase bonding, glass solder, Sintering is established as a suitable high temperature die attachment techniques. And each method can be applied appropriately to application requirements.
$\mathrm{Si}$ and $\mathrm{SiC}$-based power devices, Electronic Components and Technology Conference (ECTC) , 2015 IEEE 65th; doi: 10.1109/ECTC.2015.7159903

[3] Roderich zeiser, Suleman Ayub, Jochen Hempel,Michael Berndt and Juergen Wilde, "Mechanical stress analyses etc of Packaged Pressure Sensors for Very High Temperatures, Journal of Microelectronics and electronics packaging, 2014.,pp.3035,doi:10.4071/imaps.399

[4] Roderich Zeiser, Advanced process and production technologies for micro systems made of metals, Silicon and polymers (IMTEK Freiburg),Vol. 172015

[5] Adeel Ahmad bajwa, New assembly and packaging technologies for high-power and hightemperature GaN and SiC devices (IMTEK Freiburg), DOI: 10.6094/UNIFR/10311

[6] Roderich Zeiser, Phillip Wagner, Juergen Wilde, Assembly and packaging technologies for hightemperature SiC sensors, Electronic Components and Technology Conference (ECTC), 2012 IEEE 62nd; doi: 10.1109/ECTC.2012.6248852

[7] I. Y. Chien, M. N. Nguyen, "Low stress polymer die-attach adhesive for plastic packages," Proc $58^{\text {th }}$ Electronic Components \& Technology Conf, Washington, FL, May. 1994, pp. 580-584.

Tab. 3: Process parameters and requirements of die attach methods[1][2]

\begin{tabular}{|l|c|c|c|}
\hline & $\begin{array}{l}\text { Operation } \\
\text { Temperature }{ }^{\circ} \mathrm{C}\end{array}$ & $\begin{array}{c}\text { Process } \\
\text { Temperature }\end{array}$ & $\begin{array}{c}\text { Metal } \\
\text { Requirement }\end{array}$ \\
\hline Solder & $<200$ & 221 & YES \\
\hline Adhesive & $100-150$ & $120-180$ & NO \\
\hline TLP & $200-400$ & 250 & YES \\
\hline Sinter & 500 & $210-235$ & YES \\
\hline Glasssolder & 650 & 700 & NO \\
\hline
\end{tabular}

\section{References}

[1] E. Möller, A. Bajwa,E.Ratjagaev,J.Wilde Comparison of new die-attachment technologies for power electronic assemblies, Electronic Components and Technology Conference (ECTC), 2014 IEEE 64th; doi:10.1109/ECTC.2014.6897527

[2] A. Bajwa, E. Möller,J.Wilde Die-attachment technologies for high-temperature applications of 